\title{
From Justified Emotions to Justified Evaluative Judgements*
}

\author{
JULIEN A. DEONNA University of Geneva \\ FABRICE TERONI University of Bern
}

\begin{abstract}
Are there justified emotions? Can they justify evaluative judgements? We first explain the need for an account of justified emotions by emphasizing that emotions are states for which we have or lack reasons. We then observe that emotions are explained by their cognitive and motivational bases. Considering cognitive bases first, we argue that an emotion is justified if and only if the properties the subject is aware of constitute an instance of the relevant evaluative property. We then investigate the roles of motivational bases. Finally, we argue that justified emotions are sufficient for justified evaluative judgements.

RÉSUMÉ: Existe-t-il des émotions justifiées? Peuvent-elles justifier certains jugements évaluatifs? Nous commençons par constater qu'une analyse des émotions justifiées est souhaitable car les émotions sont des états sensibles aux raisons. Nous soulignons ensuite que les émotions s'expliquent par leurs bases cognitives et motivationnelles. Notre examen des bases cognitives nous conduit à soutenir qu'une émotion est justifiée si et seulement si le sujet est conscient de propriétés qui constituent une instance de la valeur pertinente. Nous considérons ensuite les rôles des bases motivationnelles et donnons enfin des raisons de penser que les émotions justifiées peuvent justifier certains jugements évaluatifs.
\end{abstract}

* We are grateful to Anja Berninger, Roger Crisp, Sabine Döring, Eva Düringer, Julien Dutant, Peter Goldie, Anita Konzelmann Ziv, Federico Lauria, Anika Lutz, Adam Morton, Kevin Mulligan, Bence Nanay, Raffaele Rodogno, Sabine Roeser and Mikko Salmela for their very helpful comments on a previous version of this paper.

Dialogue 51 (2012), 55-77.

(C) Canadian Philosophical Association/Association canadienne de philosophie 2012 doi:10.1017/S0012217312000236 
We often pass evaluative judgements as a result of experiencing emotions. John judges that the joke is funny because he is amused by it. Mary judges the remark to be offensive because she is angry at its author. It is thus natural to think that emotions often explain, at least in part, our evaluative judgements. This phenomenon we take for granted. Our focus will be on the epistemological role emotions may play in connection with evaluative judgements, and in particular on whether justified emotions are apt to justify the judgements they often explain. This problem requires that we answer the following two questions. First, under which conditions are emotions justified? Second, which epistemological role(s) can justified emotions play in connection with evaluative judgements?

We first motivate the need for an account of justified emotions by considering some central disanalogies in the respective epistemological roles of emotions and perceptions vis-à-vis the judgements they explain (section 1). In a nutshell, the possibility of asking why-questions about the emotions shows that emotions are, as opposed to perceptions, states for which we have or lack reasons. In section 2, we reject an epistemological picture - the idea that emotions are preceded by axiological judgements or value intuitions - that these disanalogies may foster, but that we perceive as wrongheaded. On the basis of this conclusion, we then develop our own account of justified emotions. We observe, in section 3, that why-questions about the emotions can be answered by reference to what we call the emotions' cognitive and motivational bases. In section 4 , we focus on cognitive bases and put forward the claim that an emotion is justified if and only if the properties of which the subject is aware constitute an instance of the evaluative property that features in the correctness conditions of this emotion. Sections 5 to 7 are devoted to some potential problems this claim confronts. We first argue that there is no gap between the conditions put forward by this claim and what must ultimately be considered sufficient for an emotion to be justified (section 5). Next, we focus on the role of motivational bases. In section 6 , we investigate whether they play positive epistemological roles, and in section 7 whether they are detrimental to the justification of emotions. The final section centres on the connection between justified emotions and justified evaluative judgements: we argue that the former are sufficient for the latter and that emotions are not epistemologically superfluous.

We should emphasize at the outset that the questions about justified emotions and their epistemological role presuppose, at least for the way in which we shall treat them, the existence of interesting links between types of emotions and types of evaluative properties. More specifically, we shall take for granted that emotions have correctness conditions and that these must be couched in evaluative terms. On this picture, the correctness of fear has to do with the dangerousness of the object at which fear is directed, the correctness of anger with an object's offensiveness, that of sadness with the fact that something constitutes a loss, etc. ${ }^{1}$ Our focus will be, first, on the conditions under 
which emotions so conceived are justified, and second, on the epistemological relations they stand in to what we shall call the corresponding evaluative judgements: those that attribute to an object, event or state of affairs the evaluative property that features in the correctness conditions of the emotion that explain them. ${ }^{2}$

The claim that there exists a connection of this nature between emotions and evaluative properties is shared by many contemporary approaches to the emotions. ${ }^{3}$ However, even if there is a widespread endorsement of this claim, its consequences for the epistemology of emotions and evaluative judgements often have not been raised. One recent approach that has devoted some attention to this issue is the conception according to which emotions are forms of affective perception. ${ }^{4}$ Indeed, this approach is partly motivated by the idea that the epistemological connection between emotions and evaluative judgements mirrors that between perceptions and perceptual judgements. An enquiry into justified emotions will therefore profit from considering whether this is the case.

\section{Perceptions vs. Emotions}

Under which conditions are perceptual judgements justified? Well, it is reasonable to think that one is justified in judging that there is a red circle in front of one when one has an experience as of a red circle and no reason to consider this experience illusory or otherwise misleading. That is to say, perceptual experiences provide defeasible justification for perceptual judgements. ${ }^{5}$ Straightforwardly modelling the epistemology of evaluative judgements on that of perceptual judgements would then mean that an emotion justifies the corresponding evaluative judgement in the absence of reasons to think it is incorrect. Say one is amused by a joke, afraid of a dog, angered by a remark or ashamed of one's behaviour and has no reason to think that one's emotional response is incorrect. It may then appear reasonable to think that one's judgements that the joke is funny, the dog dangerous, the remark offensive and the behaviour degrading are justified. However, even though the claim that there exists such a direct epistemological connection between emotions and evaluative judgements is sometimes counted amongst the virtues of the perceptual approach, this claim raises the following worry.

Notwithstanding the reasons for which epistemologists maintain that perceptual experiences justify perceptual judgements - because these experiences put us in direct cognitive contact with the relevant objects and properties, or because these experiences are reliably caused by them, etc.- the basic reason why this claim is so appealing traces back to the following: answers to whyquestions concerning perceptual judgements reach rock bottom when reference is made to a perceptual experience there is no reason to distrust. "I (seem to) see one" is a good and definitive answer to "Why do you think there is a yellow station wagon in the street?" And, surely, the way we conceive of perceptual experiences as apt to end the quest for justification in this way is symptomatic 
of our conceiving them to be primary modes of access to the relevant objects and properties.

None of these points apply to the emotions, however. Not only do emotions provide odd answers to the relevant why-questions, but even when we accept them as such they definitively do not end the quest for justification in relation to evaluative judgements. Thus, even if "I am angry at it" can provide an answer to the question "Why do you think the remark is offensive?", we are likely to go on to ask "But why are you angry at it?"

This observation proves crucial for the issues we shall confront. Indeed, it shows that emotions are states for which we have or lack reasons, i.e. states that, as opposed to perceptions, can be justified or not. Now, what we have just seen suggests that emotions are states for which we have or lack reasons because they are not primary modes of access to evaluative properties in the way perceptions are primary modes of access to, say, the sizes, shapes and colours of objects in our immediate vicinity. The possibility of asking the further question "But why are you angry?" seems to suggest, against the perceptual approach, that emotions should be conceived as reactions to the subject's prior and non-emotional awareness of evaluative properties ("Well, the remark is obviously very offensive!").

This striking epistemological disanalogy with perception is something we should try to explain. If justified emotions depend on awareness of evaluative properties, then what form does this awareness take? Our next task consists in exploring whether it must take the form of evaluative judgements or value intuitions. ${ }^{6}$

\section{Judgements and Intuitions}

If the reasons we typically give in favour of emotions refer to the object's evaluative properties, we may want to explain this fact by suggesting that (justified) emotions are reactions to (justified) evaluative judgements. ${ }^{7}$ The claim is that one experiences justified fear of the dog only if one has come to a justified judgement as to its dangerousness, as one experiences justified shame only after having justifiably judged that one's action is degrading.

First, note how unconvincing this conception of justified emotions is. It just does not seem right to count as unjustified all those emotions that are obviously not preceded by endorsements of the relevant propositional contents. Not only does this conception imply that animals and young infants cannot have justified emotions ${ }^{8}$, something we may regret, but it also proves unconvincing for more sophisticated subjects. We do not question the justification of a person's anger upon, say, being verbally abused for his origins because his anger is not based on a judgement as to the offensiveness of the remark. Second, this picture puts a strange spin on the problem as we initially set it up. We took it for granted that evaluative judgements are often passed as a result of the emotions we undergo. Yet, if we go along with the conception under discussion and claim that justified emotions depend on evaluative judgements, then we simply 
cannot appeal to the former to explain (and potentially justify) the latter. ${ }^{9}$ Third, and in direct connection, this conception is unable to resolve the problem raised by the existence of why-questions about the emotions. Evaluative judgements are not legitimate ends in the quest for justifying emotions, since they themselves stand in need of justification; why we make these evaluative judgements is after all the question we started with.

If the subject's awareness of the reasons for his emotions does not take the form of an evaluative judgement, then an attractive alternative consists in appealing to a less demanding type of evaluative cognition: emotions are reactions to value intuitions or, as Mulligan suggests, to apparent or real feelings of value. ${ }^{10}$ One's fear of the dog is justified if and only if it is a reaction to one's intuiting or seeming to intuit its dangerousness. This suggestion, it is true, does not fall prey to the problems affecting the claim that emotions depend on evaluative judgements. Still, it faces some serious difficulties of its own.

First, the claim that we are endowed with a capacity to intuit evaluative properties should be met with scepticism. Talk of value intuitions suggests a sort of immediate, quasi-perceptual acquaintance with these properties. Yet, no convincing evidence in favour of the existence of such a form of acquaintance has been adduced and one is as a result left in the dark as to its nature. Second, and in direct connection with this point, if value intuitions are conceived as a distinct sui generis type of mental states, then they just look like ad hoc postulates introduced so as to resolve the present epistemological problem. Not only have we been presented with no positive reason to think that value intuitions exist, but we shall see below that this problem can be resolved without appealing to them. ${ }^{11}$ Third, the claim that value intuitions are apt to solve the epistemological problem raised by the existence of why-questions about the emotions is also open to discussion. Is it plausible to maintain that an emotion is justified simply because it is grounded in such an intuition? If the only thing you have to say in favour of your anger is that you somehow intuited the offensiveness of a remark that I incline to consider to be perfectly innocent, then you will no doubt fail to alter my assessment of your anger as unjustified.

So, not only do the two conceptions we have discussed here face serious difficulties, they also fail to solve the problem we are trying to address. And they fail to solve it for the same reason: neither evaluative judgements nor value intuitions put an end to the justification of emotions. We should therefore reject the idea that emotions, being reason-responsive states, depend on evaluative judgements or value intuitions. If that is so, then what if anything puts an end to the justification of emotions? The answer requires taking a closer look at why-questions about the emotions, a task to which we now turn.

\section{Back to Why Questions}

In this section, we shall distinguish two kinds of answers to why-questions about the emotions and will then use them to build an alternative account of justified emotions. 
First, why-questions are typically answered by reference to the various cognitive bases that emotions may have. The occurrence of an emotion, as opposed to the occurrence of a perception, always presupposes a mental state that is about the object of the emotion. Perception provides a direct access to objects and facts in the sense that it does not depend on another mental state directed at these very objects and facts. Emotions must, by contrast, latch on to objects provided by other type of mental states, such as perceptions, of course, but also memories or beliefs.

Answers to why-questions of the first kind articulate the content of these cognitive bases. "Why are you afraid of the lion?" "Well, I see it staring at me and approaching fast!" The answer proceeds here by explaining the subject's way of apprehending those aspects of the situation in the light of which her emotion is assessed as correct or incorrect. Typically, the question is due to the questioner's not being aware of some features of that situation, and it is sensibly answered by reference to the content of the subject's cognitive base. Full answers along these lines proceed by mentioning some further properties of the subject as well as some relations between her and the emotion's object. In the "lion" case, such an answer would mention, say, the facts that the subject is made of flesh and blood as well as spatial relations and some other types of relations between her and the animal.

Of course, the issue is more complicated when emotions are based on mental states like beliefs that can be assessed, in turn, as justified or not. You may, for instance, know that Sylvia owns a lot of German bonds and know that their value will be substantially affected if BMW is sold to a Chinese corporation, and yet question the justification of her fear by wondering whether her belief that BMW is going to be sold is justified. "Why is she afraid she will lose her fortune?" should in this context be understood as "Why does she think she might lose her fortune?" And here, you may be satisfied on learning that Sylvia has access to confidential information in light of which the deal is very likely. Simple or more complex answers to why-questions proceeding along these lines we call cognitive base answers.

Second, why-questions can receive another kind of answer because the occurrence of emotions is often if not always susceptible to rich explanations in terms of the subject's motivational profile, and this again contrasts in some important respects with perceptual states. Desires, sentiments and concerns often prove crucial for the occurrence of an emotion. An episode of shame may for instance be explained by the fact that one is attached to one's privacy. Mark's pride at this little girl winning the prize becomes clear upon learning that she is his beloved niece. Answers to why-questions that proceed along these lines we shall call, for lack of a better term, motivational base answers.

Now, on the face of it, neither cognitive base nor motivational base answers to why-questions must refer to value judgements or value intuitions. Does this mean that we can develop an account of justified emotions that does without them? 


\section{Justified Emotions}

As was made apparent in the previous section, the cognitive base of an emotion need not and typically does not contain an evaluative judgement or a value intuition. This is the case, for instance, when fear is explained by the subject's awareness of a dog with big teeth and an erratic behaviour. If we think for that reason that emotions can be justified independently of antecedent value judgements or value intuitions, there must be an intimate relation between the content of the cognitive base and the emotion that this cognitive base explains, a relation that makes room for the claim that awareness of the former justifies the latter. And, since emotions have correctness conditions that must be couched in evaluative terms, this means that awareness of the cognitive base's content must be apt to justify a mental state that is correct if and only if a given evaluative property is exemplified. So, which relation between the content of the cognitive base and the evaluative property featuring in the emotion's correctness conditions must hold, such that awareness of the content of the cognitive base justifies the emotion?

We suggest that the relation we are after is one of constitution between evaluative and non-evaluative properties. ${ }^{12}$ To say that an object's exemplification of an evaluative property is constituted by its exemplification of non-evaluative properties is to say that this object exemplifies the former in virtue of or because of its exemplifying the latter: there is a sort of token identity here. While this raises the question as to whether or not this ontological relation is further explainable (can it, for instance, be explained in terms of a specific form of strong supervenience of evaluative properties on non-evaluative properties?), we shall not further discuss this issue here. ${ }^{13}$ For the idea that we want to put to use in our discussion is simply that an object exemplifies a given evaluative property at a given time and in a given context in virtue of its exemplifying some non-evaluative properties. For instance, at a given time and in a given context, a dog's dangerousness is constituted by its having big teeth and its behaving erratically.

This opens the way for an attractive account of justified emotions, since it allows for the possibility that the properties constituting an evaluative property feature in the content of mental states that are neither axiological judgements nor value intuitions. For instance, there is no need to judge that the dog is dangerous or to somehow intuit its dangerousness in order to be aware of its big teeth and erratic behaviour. This suggests the following account of justified emotions:

An emotion is justified if and only if, in the situation in which the subject finds herself, the properties she is (or seems to be) aware of and on which her emotion is based constitute (or would constitute) an exemplification of the evaluative property that features in the correctness conditions of the emotion she undergoes. 
Suppose that a dog with big teeth and erratic behaviour constitutes, given the circumstances in which Sam finds himself, a danger. The idea is that his fear is justified if it is based on his awareness of this dog, its big teeth and erratic behaviour. ${ }^{14}$ The epistemological claim distinctive of this account is thus that, if a relation of constitution obtains, awareness of the properties that constitute the evaluative property justifies an emotion whose correctness conditions make reference to that property. For that reason, justified emotions need not be based on evaluative judgements or value intuitions.

The idea that justified fear must rest on an apprehension in evaluative terms of that which makes the fear correct may still seem irresistible. Yet, this idea can and should be resisted once it is realized that the subject is credited with an awareness of properties that constitute danger. ${ }^{15}$ For, if danger is constituted by the instantiation of some non-evaluative properties, there is no further fact of the matter, nothing more to a specific danger than the instantiation of what makes it a danger. A dog with big teeth and an erratic behaviour constitutes a danger, as the death of a person may constitute a loss or a specific remark uttered in a specific context may constitute an offense. An instance of danger, loss or offensiveness is not a further property by the side of those properties that constitute it. ${ }^{16}$ If awareness of these properties explains why a subject undergoes the relevant emotion, then this emotion is explained by the subject's awareness of an instance of the relevant evaluative property, and this seems sufficient to justify it.

We have just offered an account of justified emotions that dispenses with evaluative judgements and value intuitions. We shall now elaborate on it by considering some important issues it raises. In section 5, we discuss the claim that our account does not do justice to the nature of the emotions' cognitive bases. In sections 6 and 7, we shall scrutinize problems that have to do with the nature and role of their motivational bases.

\section{The Gap}

The first worry is motivated by the thought that there is an important gap between awareness of properties constituting an instance of an evaluative property and what justifies a given emotion. After all, it seems possible for a subject aware of these properties to fail to grasp their "normative significance", that is, that they are the reasons they are. According to the present worry, this shows that, to justify an emotion, awareness of a specific danger must be supplemented by awareness of its normative significance, which consists in making an evaluative judgement. ${ }^{17}$

There are three distinct interpretations of the claim that one might fail to grasp as a reason a danger of which one is aware. (a) The idea might be that being aware of a danger is not sufficient to explain the occurrence of fear. (b) It might be that this is not sufficient for one to realize that one faces a motivationally relevant situation. (c) Finally, one might think that it is insufficient to explain one's realizing that danger is apt to justify one's emotion. 
The suggested conclusion is that, whichever of these interpretations we favour, the existence of a gap shows that emotions in general, or justified emotions more specifically, require the making of evaluative judgements. So, let us consider these interpretations in turn.

(a) Note that, in the previous section, we have only laid out a condition on the contents of cognitive bases that we think is sufficient to justify the emotions they explain and said nothing about what is required for awareness of the former to explain the latter. And it is correct to emphasize, in line with the first interpretation of what the gap consists in, that awareness of a content meeting this condition is not sufficient to explain why an emotion occurs. Awareness of a specific danger for instance is insufficient to explain the occurrence of fear: we have seen in section 3 that desires, cares and concerns are likely to play a crucial role in such explanations and we shall investigate in the next section what this shows about the justification of emotions. For now, we want to focus on the following issue. It seems that combining the relevant motivational state with the awareness of an instance of a given axiological property is still insufficient to explain why the emotion occurs. One can be aware of a specific danger, be motivated to preserve one's physical integrity, yet not feel afraid. Should we, in light of the possibility of such a gap, supplement our account with evaluative judgements? Here is why we do not think so.

First, such a possibility does not always arise. In the most primitive cases, the subject is simply 'wired' in such a way that perceptual awareness of some properties elicits an emotion. This is in all probability the case for the fear predators elicit in some animals and more generally for the elicitation of many emotions often referred to as "affect programs". ${ }^{18}$

Second, explaining why emotions are elicited in more complex cases need not refer to evaluative judgements. A subject may for instance have to learn that animals with such and such features are likely to attack. As a result of such learning, perception of the relevant properties gets associated with the likelihood of an attack and elicits fear. But this explanation does not refer to an evaluative judgement: we have simply credited the subject with a specific recognitional capacity. Once this capacity, which partly explains why the emotion occurs, is in place, the justification of fear depends on whether it is due to (apparent or real) perceptual awareness of properties constituting danger. Whether or not the subject had to learn to discriminate the relevant properties, these are cases in which the emotion is justified because it is based on a perception with a specific content. ${ }^{19}$

Now, of course, the justification of emotions does not always take this form. When the emotion is based on a non-perceptual belief, there is room for further epistemological questions that target the justification of this belief. Is Sylvia's belief that she might lose her fortune, a belief on which her fear is based, justified? In these more complex cases, the subject cannot access the relevant properties through perception, but only via complex cognitive states. And it may be the case that mastery of the relevant evaluative concept is needed to extend in this 
way the range of fear-eliciting situations. Yet, this does not support the conclusion that Sylvia's fear is justified only if she judges that she confronts a dangerous situation. What we should rather say is that she is now, in virtue of having been through a complex learning process, apt to react with fear to various situations. And her fear is justified if her beliefs about those facts that make these situations dangerous are themselves justified. ${ }^{20}$

(b) Let us now turn to the second interpretation of what the gap consists in, i.e. the claim that there is nothing in our account to ensure that the subject realizes that he faces a motivationally relevant situation. Yet, if we favour this second interpretation, it is difficult to see why evaluative judgements would fare any better than emotions in bridging the gap. Indeed, while emotions are according to most theories directly motivating states, no such thing is true of evaluative judgements until contentious forms of motivational internalism are shown to be correct. Are not emotions precisely attitudes consisting in a readiness to act in various and distinctive ways vis-à-vis a given object or situation? ${ }^{21}$ That being so, if realizing that the situation one confronts is normatively significant means realizing its motivational relevance, a subject undergoing an emotion based on the content of his awareness displays a grasp of its normative significance, as opposed to another who only judges that the situation exemplifies a given evaluative property.

(c) Assessing the third interpretation of what the gap consists in is less straightforward. The thought is that our account misses the fact that a justified emotion presupposes that the subject be aware that it is (would be) appropriate. ${ }^{22}$ Indeed, neither the subject's awareness of the situation (awareness, say, of a dog with sharp teeth), nor his having the emotion (fearing the dog) is identical to awareness that it is appropriate to have it: emotions cannot refer to their own appropriateness in that way. ${ }^{23}$ And, if that is so, then awareness that one's emotion is appropriate can only consist in the making of this very evaluative judgement.

Now, there is a view according to which judging that an object has a given evaluative property states that a given emotion towards it would be appropriate. ${ }^{24}$ Whatever the merits of this normative approach to evaluative judgements, it has little to recommend itself in the case of justified emotions. ${ }^{25}$ First, such an approach would fly in the face of the phenomenology. When we undergo emotions, we seem to be entirely directed 'outwards' to the world and its properties, and in no way 'inwards' to responses that would be appropriate in the circumstances. ${ }^{26}$ Whether or not it is justified, an episode of sadness, anger or amusement does not seem to be preceded by a mental act commenting upon the normative credentials such emotions would possess. Second, this normative approach to evaluative judgements appears to require the existence of properties exemplified in the circumstances and apt to justify the emotions that respond to them. What this strongly suggests is that the predicates "appropriate" and "justified" mean, when applied to the emotions, what they are customarily taken to mean in other areas of discourse, namely that there are good and 
undefeated reasons for representing the facts as these emotions do. This would make sense of why the corresponding evaluative judgements deem them appropriate. After all, we often explain why the relevant norms bear on the circumstances by reference to evaluative properties: one ought to fear because the situation is dangerous, or one ought to admire this painting because it is beautiful.

To sum up, however the gap is interpreted, nothing in the relevant phenomena supports supplementing our account with evaluative judgements. If the gap is understood along explanatory lines, then we should credit the subject with the relevant recognitional capacities. If we prefer to understand it along motivational lines, then emotions themselves can bridge it. And if it is understood along normative lines, then it betrays a presupposition according to which the justification of emotions should be exclusively elucidated in the light of the fact that evaluative judgements normatively comment on them.

\section{An Internalist Worry: Access}

We have seen that why-questions about the emotions are typically answered by reference to their cognitive and motivational bases. Why does Tom feel ashamed in the circumstances? He realizes he has forgotten to give his niece a present (cognitive base), a child to whom he is very attached (motivational base). Now, both kinds of bases may be thought to contribute to the justification of emotions and the question arises as to whether the subject must access these bases in order for his emotion to be justified. To assess whether or not this form of internalism should be endorsed, we have to get clear as to what contributes to the justification of emotions. While we have already seen that cognitive bases play a crucial role in this connection, nothing yet has been said regarding whether the same is true of desires, cares and concerns. Our claim in this section is that, if it is correct to think that motivational states play such a justificatory role - and we shall give reasons to doubt it - there is no reason to think that the justification of emotions depends on the subject's being aware of them.

Let us start by observing that why-questions about the emotions are ambiguous. "Why does $\mathrm{S}$ have emotion $x$ ?" can be read either as a question about why $\mathrm{S}$ comes to have this emotion about this object (one asks for explanatory reasons) or it may be a question about his justification for having it (normative reasons). And it seems quite natural to think that mentioning the desire to have a beer in connection with an episode of disappointment provides an explanatory reason as opposed to a normative reason for this emotion. Why not generalize this point so as to conclude that motivational states play no justificatory role vis-à-vis emotions? This is the conclusion we incline to favour, yet two views support the idea that it would be too hasty. First, one may think that motivational states contribute to justification because emotions inherit their justified or unjustified character from that of these motivational states. Alternatively, one may think that their contribution to the justification of emotions traces 
back to the fact that they (partly or wholly) constitute the evaluative property that features in the correctness conditions of emotions. Let us examine these two views in turn.

According to the first view, emotions are not only explained by motivational states: in addition, the former inherit their justified or unjustified character from that of the latter. Mark's pride at this little girl's winning the prize is surely explained by his love for her, but the suggestion is that the contribution of his love goes beyond that: the justification of his emotion is inherited by that of his love. Similarly, fear is justified to the extent that the care for one's physical integrity that explains it is itself justified.

The first observation to make is that this view puts some severe constraints on the nature of cares and concerns. They cannot be conceived, as they often are, as dispositions individuated in terms of their manifestations, among which emotional episodes are central. For, if dispositions (or their categorical bases) can explain their manifestations, this explanation does not seem to carry any justificatory implication. For instance, judgements that $p$ are amongst the manifestations of the belief that $p$ and someone's believing that $p$ can surely explain his judging that $p$. Yet, the belief that $p$ cannot justify the judgement that $p$, for it is simply not a reason in favour of this judgement. This carries over to the relation between cares and concerns on the one hand and emotions on the other insofar as we think of the former as being dispositions to undergo emotions. The nature of this relation is simply incompatible with the claim that emotions inherit their justification from the justification of the cares and concerns they manifest.

This means that, in order to say that there are justificatory relations between cares, concerns and emotions, one must quite controversially conceive of cares and concerns not merely as dispositions to undergo emotions, but rather as something like long-lasting affective states that are independent of the emotions to which they give rise. Mark's love for his niece is now conceived as a long-standing intentional relation to her that can be justified only if there is evidence for her being loveable. It is also claimed that the emotions to which these states give rise - an episode of pride at his niece's achievement - inherit their justification from that of these states. Note that this is not to be confused with the idea that, to the extent that an emotion is explained by an unjustified care or concern, this defeats its justification. The claim is much stronger: the emotions inherit their justification from the justification of the cares and concerns that explain them.

The plausibility of this view depends on its ability to build a case against the following intuitions. First, not only do many of our cares and concerns seem to emerge from a series of discrete emotions about their object, but the justification of the former seems also to depend on that of the latter. Intuitively, it makes more sense to say that my love for all things Shakespearian inherits its justification from the many specific and distinct justified emotional experiences his works have elicited in me and out of which my love has emerged than the other 
way around. Second, the advocate of this view will have to explain away the intuition that many emotions - like the admiration one may feel on discovering an artist's work - do not seem to trace back to any long-standing intentional relation, and a fortiori, to one from which they can inherit their own justification.

If these challenges can be met and it is indeed correct to maintain that emotions always inherit their justification from that of the cares and concerns that explain them, then it might be thought that no emotion is justified unless the subject is aware of these cares and concerns. Before we enquire as to whether this is the case, let us examine the second view that motivates the idea that cares and concerns justify emotions.

According to this second view, motivational states contribute to the justification of emotions not because they are themselves justified or unjustified, but rather because they partly constitute the evaluative properties to which emotions respond. For instance, caring for one's physical integrity should be counted amongst the properties that constitute a specific danger. It is easy to see why this view motivates the idea that cares and concerns contribute to justification. The idea is simply that, because cares and concerns constitute the evaluative property to which an emotion responds, the subject is justified in responding with a given emotion only insofar as he is (or has reasons to think he is) in the relevant motivational state. And this may well motivate the thought that the contribution of these cares and concerns to the emotion's justification depends on the subject's being aware of them.

It is fair to say that the view about the ontology of evaluative properties that supports this conclusion is at least as controversial as the view about the nature of cares and concerns we have just examined. Without entering here into the difficulties attending such a view (see Deonna and Teroni, 2012, Ch. 4) let us simply observe that the fact that why-questions about the emotions are often answered by reference to motivational states does nothing to support it. These answers appear to have the function of explaining why the relevant emotion is undergone rather than that of explaining why it is correct. This is especially clear in all those cases in which reference to motivational states is made to explain why unjustified emotions occur, a phenomenon to which we shall turn in the next section.

For now, we have seen that two views support the idea that motivational states contribute to the justification of emotions. While we have suggested that these views are not without problems, we shall now suppose that this idea is at least sometimes correct so as to put ourselves in a position to assess whether it supports the further claim that their contribution to justification implies that the subject be aware of them.

Let us start discussing this issue by first answering the question of awareness in relation to cognitive bases. As we have seen, an emotion's justification depends on the content of these cognitive states, and we have already observed that the subject must be aware of these contents for his emotion to be justified. 
Now, meeting this requirement is unproblematic in many cases, as when the emotion is based on perceptions or memories, for we paradigmatically have access to these states and their contents. Things may be thought to be different, however, when the base is constituted by a belief whose justification depends, say, on the validity of a complex inference. For Sylvia's fear to be justified, what sort of access should she have to the complex reasons that support her belief that she might lose her fortune? The soundness of our account is, it seems to us, independent of the way this question is answered. We may think that the subject must be aware of the complete chain of reasons in favour of her belief that she might lose her fortune. Or we may be satisfied with the requirement that she is disposed to be aware of them. More modestly yet, we may only require that she did form these beliefs at some point and has not changed her mind. While we incline for the latter, the reader is encouraged to bring to bear whatever constraint she thinks must be met for the target belief to be justified, since this would not prove detrimental to the approach we recommend.

We think it would be ill-advised to be as concessive as regards the awareness requirement for motivational states, however. The claim that the content of the subject's awareness justifies an emotion only if he has the relevant motivational state does nothing to show that it contributes to the justification of the subject's emotion only if he articulates it or would be able to articulate it if prompted. On the face of it, this indeed appears quite questionable. There seems to be no reason to think that, for Mark's pride over his niece's achievement to be justified, he must be aware of his love for her, or be able to articulate that love. After all, even if his pride came as a total surprise to him, this would still not carry the implication that it is unjustified. Insisting on such an awareness requirement would be to overlook a familiar and important contrast, that between justification and the capacity to articulate the reasons why one is justified.

Being justified in judging that so-and-so or in feeling an emotion is one thing, having the capacity to articulate why one is justified in making this judgement or in having this emotion quite another. As a matter of fact, this distinction between justification and the ability to show that one is justified is part and parcel of most epistemological views. ${ }^{27}$ Consider for instance the idea that perceptual judgements are justified by specific perceptual experiences provided that perception is reliable and the subject has no reason to think it is unreliable. Articulating why one is justified in making a specific judgement is a sophisticated procedure that relies on the capacity to think about perception and judgements. Yet, there is no reason for thinking that justified perceptual judgements depend on this capacity. ${ }^{28}$ The reliability of perception should rather be conceived as a background condition for the relevant perceptual justification to function as such, a background condition there is no need to articulate for making justified perceptual judgements.

If one thinks that cares, concerns and desires contribute to the justification of emotions, then our suggestion is that one should allocate to them a similar role: one should conclude that the content of the subject's awareness justifies his 
emotion given a psychological background containing these desires, cares and concerns. ${ }^{29}$ The latter are part of the psychological situation in which he finds himself and which makes it the case that the properties of which he is aware justify his emotion. Thus, even if motivational bases contribute to the justification of emotions - and we have seen how controversial the views on which this claim rests are - we should not extend the awareness requirement to encompass these motivational bases.

\section{An Externalist Worry: Reliability}

The third and final worry can also be approached from the vantage point provided by emotions' motivational bases. Whether we think that motivational states only explain or also justify emotions, the truth is that reference to motivational states often explains why unjustified emotions occur. Our personal attachments, obsessions, or idiosyncratic interests are well-known to have distorting effects on our emotional lives. The worry is that the pervasiveness of this phenomenon reflects badly on what we have said so far. The thought here is that our account wrongly presupposes that emotions reliably track evaluative properties. Yet, since emotions are unreliable, the mere absence of reasons to think the relevant properties are not present — as our account has it - is not enough for a justified emotion. The subject rather needs to ascertain the presence of positive reasons to think that, in the circumstances, his emotion tracks the evaluative facts.

Let us agree with the following. If, for all of us or for the subject, emotions in general or a given emotion type in particular prove very unreliable, then our account is misguided. For the kind of justification we favour may indeed not survive amidst pervasive unreliability: the fact that an emotion responds to the relevant evaluative facts would be no more than a lucky event. However, are we really in such a predicament? Here are reasons for some optimism.

First, to borrow Goldie's phrase, it would be rash to conclude that motivational states systematically "skew the evaluative landscape" 30 . Some clearly do: love may elicit unwarranted admiration and anger may stem from grumpiness or irascibility rather than from anything that would justify it. These biases do not preclude the subject from having justified admiration or anger, but then he must surely have reasons to think that his response is not exclusively due to these motivational states. ${ }^{31}$ That being said, if motivational states did always distort our apprehension of the evaluative domain, this would have serious sceptical consequences. For we know that when motivational states exert distorting effects, these effects are not confined to our emotional responses, but also affect our search of reasons for these responses, and more generally, a wide range of evaluative judgements. ${ }^{32}$ The potentially distorting effects of love extend well beyond the elicitation of unwarranted emotions like admiration to our unjustified judgements about there being reasons to admire, and more generally, to unjustified evaluations of various objects. ${ }^{33}$ So, if motivational states with such damaging effects did always lurk in the background, this 
would deprive us of any safe access to the evaluative domain. This sceptical conclusion can only be resisted if we admit that the above epistemological consequences only pertain to problematic motivational states: not all of them prove detrimental to the idea that emotions can be justified along the lines we recommend.

Second, and in close connection to the point just made, the significance of the present worry depends on how we demarcate the domain relevant for assessing whether an emotion manifests a capacity to reliably track the evaluative facts. Consider anger and suppose that you are angry at a sexually offensive remark. For your emotion to be justified, should it manifest a capacity to track the sexually offensive, the offensive in general or a more extended domain of evaluative facts? After all, you may be able to reliably track only the first property. And if, for a given emotion to be justified, it is required that reliable tracking extends well beyond the type of case at hand, then justified emotions may be hard to come by. Yet, it is difficult to see why such a requirement would be relevant for the justification of any given emotion. Why think for instance that one's competence in tracking slight-to-honour-based offenses is relevant for assessing the reliability of an emotion responding to the sexually offensive? And if the requirement over reliable tracking applies for that reason to a more limited domain, then the answer to the present worry should proceed in a careful, piecemeal fashion, i.e. by considering whether the subject's emotion manifests a capacity to track, say, the sexually offensive in a variety of contexts. If it does, then the subject needs no additional reasons for his emotion.

Third and finally, let us observe that the claim that emotions are unreliable may be motivated by considerations that have no bearing on the issue at hand. Thus, it is true that emotions often blind us to some aspects of the circumstances. Mary's anger at John, say, does not allow her to see that he faces a dangerous situation and needs help. However, this does nothing to show that the relevant emotions, like Mary's anger at John, are unreliable, only that they may make it more difficult to reach justified judgements as to the overall goodness or badness of the situation.

\section{From Emotions to Evaluative Judgements}

We have defended the idea that emotions are justified if based on awareness of properties that constitute an instance of the relevant evaluative property. We now turn to our second problem, which concerns the epistemological relations between justified emotions and justified evaluative judgements. Remember that we are interested in the relations between justified emotions and the corresponding evaluative judgements, i.e. those that take place between, say, justified anger and the judgement that so-and-so is offensive. Can justified emotions justify the corresponding evaluative judgements they explain?

The claim that seems at least initially warranted at this stage is that these evaluative judgements are justified by the content of the subject's awareness in the same way as emotions are. That is to say, if, given the situation in which the 
subject finds herself, the content of her awareness justifies fear or anger towards an object, then her judging on the basis of this same content that the object is, respectively, dangerous or offensive would also be justified. ${ }^{34}$ This claim raises two important issues, however. These respectively concern the nature of evaluative judgements and the importance of emotions in reaching evaluative verdicts. Let us examine them in turn.

The first issue concerns whether emotions can be sufficient for justified evaluative judgements. One reason to doubt that this is the case, akin to one that surfaced in our discussion of the normative gap, traces back to the idea that evaluative concepts are concepts of appropriate emotions. To judge that something is amusing is to judge that amusement towards it would be appropriate. ${ }^{35}$ Since, as we have seen, emotions cannot refer to their own appropriateness, this may appear to support the conclusion that justified emotions cannot by themselves justify the corresponding evaluative judgements.

Suppose that evaluative judgements indeed state that a given emotion would be appropriate. Does this imply that a justified emotion is insufficient for the corresponding judgement's justification, i.e. for justifiably judging that this emotion is appropriate? ${ }^{36}$ We fail to see why. A justified emotion is based on (real or apparent) awareness of properties that, in the circumstances, (would) constitute an instance of the relevant evaluative property. When one emotionally responds to these properties absent any reason to think the response is incorrect, one seems to be in a position to justifiably judge that these properties are exemplified and so to justifiably pass the corresponding evaluative judgement. To put it differently, the difficulty fades away once we remind ourselves that talk of appropriateness and justification simply refers to the fact that there are good reasons for representing the situation as the emotion and the corresponding judgement represent it. ${ }^{37}$

Hence, even if evaluative concepts are concepts of appropriate emotions, this does not support the conclusion that justified emotions are insufficient for justified evaluative judgements. Yet, consider the following line of thought. Given what we have said so far, making an evaluative judgement would seem to consist in committing oneself to there being reasons to think that an evaluative property is exemplified. Making a justified evaluative judgement would then require having good reasons to think that it is the case. So, under which circumstances does one have good reasons to commit oneself in this way? Only if, it may be suggested, one can articulate features of the situation in the light of which the judgement that the value is exemplified is reasonable. And it seems as if having a justified emotion does not in itself put one in a position to achieve that much. Suppose for instance that Jim rushes out of a conference room claiming that the situation was deeply embarrassing. What explains his judgement is the justified embarrassment he felt, which responded to various subtle clues in the audience. As he passes his judgement, however, he is unable to articulate these features. The suggestion is that the fact that the judgement is for that reason unjustified shows that justified emotions are, sometimes at least, 
not sufficient for the justification of the corresponding evaluative judgement. Should we accept this conclusion?

The following observations suggest we should not. According to our account, the mere occurrence of emotions is not sufficient to justify corresponding evaluative judgements: only justified emotions, whose justification depends on the content of their base, are sufficient. Applied to Jim's case, our claim is that, given that awareness of the relevant cues justifies his embarrassment, then his judgement that the situation is embarrassing would be justified if based on awareness of the same cues. The fact that these cues are not accessible when he judges cannot be used against this claim, since his emotion would also be unjustified if it were to take place in the same circumstances, i.e. absent any awareness of good reasons. Thus, what remains of the present worry is simply that mastery of an evaluative concept requires the ability to articulate which properties justify its application. Still, this does nothing to show that an emotion responding to these same properties is not sufficient to warrant its application, and this even though the subject would not pass the judgement if he had not acquired the relevant conceptual ability. ${ }^{38}$

These observations lead us to conclude that justified emotions are sufficient to justify evaluative judgements. Should we rest content with this conclusion, or is it possible to go beyond it? We observed above that the idea that emotions and axiological judgements have the same reasons also raises an issue concerning the importance of emotions in reaching evaluative verdicts. For this idea may motivate the thought that emotions are epistemologically superfluous. After all, if the content of one's awareness justifies an emotion, then it would have justified the corresponding evaluative judgement even though one did not experience the emotion. This is so because a justified evaluative judgement is always "in principle inferable" from the information available to the subject independently of his emotion. ${ }^{39}$ The existence of two routes to justified evaluative judgements, an emotional one and a route bypassing emotions altogether, is in our opinion beyond dispute. Yet, does this show that emotions are epistemologically superfluous?

To see why it does not, consider again Jim's judgement that the situation was embarrassing. The case illustrates the following fact: we often prove quite bad at articulating the reasons to which our emotions respond when or just after we experience them. This is important for the issue at hand, for it suggests that the conclusion the subject would reach independently of his emotion may fail to respond to the good reasons to which his emotion is in fact sensitive. ${ }^{40}$ The subject may well be emotionally attuned to the relevant reasons, but the conclusion he reaches with a cooler head fails (due to lack of intelligence, an ideological turn of mind, laziness, etc.) to envisage the relevant reasons as reasons or to give them their due weight. ${ }^{41}$ If, in such a situation, the subject passes the corresponding evaluative judgement on the basis of his emotion, perhaps with a sense that he should refrain from so judging, his judgement may well be justified despite his conflicting coolly reached verdict. We shall not 
consider here how this idea should be developed. ${ }^{42}$ Our point is simply that there appear to be judgements whose justification resists conflicting and coolly reached verdicts because the emotions that explain them respond to good reasons.

This being the case, the fact that justified evaluative judgements are in principle inferable from the information available to the subject independently of his emotions does not support the conclusion that emotions are epistemologically superfluous. Good reasons for evaluative judgements may be in principle accessible independently of emotions, yet their relevance for these judgements would be missed or distorted if one were to coolly ponder over the situation. As a result, the justification of these judgements can only be due to the fact that they are based on emotions responding to good reasons.

\section{Conclusion}

We have argued for the following account of justified emotions: emotions are defeasibly justified by awareness of properties that constitute an instance of the evaluative property that features in the correctness conditions of these emotions. None of the many worries we have reviewed support giving up this straightforward account. We have then argued that, while this account implies that there are two distinct routes originating in the same reasons to the making of justified evaluative judgements, the emotional route is not epistemologically superfluous and might well prove essential.

\section{Notes}

1 For ease of exposition, we shall omit the complications arising from the fact that evaluative properties come in degrees and that correct emotions must mirror this fact through their intensity.

2 We shall therefore not be concerned with evaluative judgements that attribute overall goodness or badness.

3 For an exploration of the links between emotions and evaluative properties, see Teroni (2007).

4 Different perceptual approaches to the emotions can be found in Deonna (2006), Döring (2007), Prinz (2004), Roberts (2001) and Tappolet (2000).

5 We skip over complications raised in this connection by some disjunctivist positions according to which only perceptions justify, as opposed to other perceptual experiences like illusions and hallucinations. As far as we can see, this does not affect our discussion.

6 Advocates of the view that emotions must be preceded by evaluative cognition are typically unclear as to what this cognition consists in. Brady (2010), for example, speaks of "non-emotional abilities to recognize and identify" evaluative properties. As we shall see, when we try to cash out what such claims may amount to, their plausibility soon becomes questionable.

7 An approach to the emotions that claims that they are always preceded by evaluative judgements is to be found in Lyons (1980). 
8 Deigh (1994) offers a detailed examination of the problems faced by approaches to the emotions in terms of evaluative judgements.

9 Perhaps the most we could then say is that the absence of an emotion after having passed the relevant evaluative judgement may sometimes defeat it ("why do I think it is funny if I am not amused in the slightest?"). For an interesting discussion of this problem, see D'Arms and Jacobson (2010).

10 Mulligan (2007, 2010).

11 This criticism of course fails to apply if by 'value intuitions' one means to refer to the emotions themselves. For such an approach, see Roeser (2011).

12 See Dancy (1993: chap. 5) and (2004: 85ff) who speaks in this connection of evaluative properties as 'resulting' from non-evaluative properties.

13 Strandberg (2008) convincingly argues against Dancy that constitution or resultance can be explained in terms of strong supervenience.

$14 \mathrm{Be}$ aware that this epistemological claim does not carry any phenomenological implication. From a phenomenological perspective, the existence of these two layers and their epistemological relation need not be salient. An episode of fear or admiration need not strike one as being composed of an affective experience based on a perceptual one.

15 For closely connected remarks, see Jackson (1998: 127).

16 Dancy (1993: 75).

17 It may also consist in intuiting a value. However, in the absence of a full-fledged account of what value intuitions are, it is unclear whether they possess the normative credentials that cognitive bases are supposedly lacking and thus how the points to be developed here apply to them.

18 For the philosophical significance of affect programs for emotion theory, see in particular Griffiths (1997).

19 The number of cases belonging to this class will vary as a function of the kinds of properties that can be accessed by purely perceptual means. For a discussion of this issue, see Siegel (2006).

20 For a more detailed reply to this first interpretation of the gap, see Deonna and Teroni (2012: 98-100).

21 We argue in favour of this approach to the emotions in Deonna and Teroni (2012: Ch. 7).

22 See for instance D’Arms (2005), McDowell (1985).

23 On this issue, see Brady (2010).

24 We are alluding here to the Fitting Attitude analysis of value. See Rabinowicz and Rønnow-Rasmussen (2004) for various historical and contemporary versions of this approach, and Deonna and Teroni (2012: Ch. 4) for an introductory exposition.

25 Unless, that is, one is already committed to a reduction of the evaluative to the normative, an idea radically at odds with the framework on which our investigation is premised.

26 This is nicely emphasized in Tappolet (2011).

27 This distinction is extensively discussed in Alston (1989).

28 See for instance Alston (1993). 
29 Schroeder (2007: Ch. 2) makes a similar suggestion in order to resolve a different problem.

30 Goldie (2008).

31 The question of whether the subject is (can be) aware of these biases proves crucial. A detailed discussion of factors that bias our responses and of their connection with awareness is offered in D'Arms and Jacobson (2010).

32 See for instance Goldie (2008).

33 As we shall see in the next section, the interplay between the reasons to which our emotions respond and those we reach via more deliberative means is less straightforward than may appear.

34 Goldie reaches this conclusion through a different route in his (2004).

35 On this influential approach to the nature of evaluative judgements, see for instance D'Arms (2005) and McDowell (1985).

36 Brady (2010).

37 Similarly, one may think that the judgement that $a$ is red states that perception of $a$ as red would be correct, something not contained in the perception of $a$ as red. But that does nothing to show that this very perception cannot justify this judgement.

38 Similarly, undefeated perceptual experiences are sufficient to justify perceptual judgements even though the subject would not have made these judgements if he had not acquired the relevant ability.

39 Peacocke (2004: 258).

40 Arpaly (2000) rightly emphasizes the importance of these sorts of cases.

41 One is reminded here of the proverbial Huckleberry Finn. For an illuminating treatment, see Arpaly (2002).

42 One may, for instance, say that the subject's judgement is justified if, absent the factors clouding his coolly reached conclusion, he would realize that the reasons his emotion responds to defeat his reasons to judge otherwise.

\section{References}

Alston, William

1989 Epistemic Justification: Essays in the Theory of Knowledge. Ithaca: Cornell University Press.

1993 The Reliability of Sense Perception. Ithaca: Cornell University Press.

Arpaly, Nomy

2000 “On Acting Rationally Against One's Best Judgement." Ethics 110: 488-513.

2002 "Moral Worth.” The Journal of Philosophy 99(5): 223-245.

Brady, Michael

2010 "Virtue, Emotion, and Attention." Metaphilosophy 41(1-2): 115-131.

Crisp, Roger

2006 Reasons and the Good. New York: Oxford University Press.

D'Arms, Justin

2005 “Two Arguments for Sentimentalism.” Philosophical Issues 15: 1-21. 
D'Arms, Justin and Jacobson, Daniel

2010 "Demystifying Sensibilities: Sentimental Value and the Instability of Affect". In The Oxford Handbook of Philosophy of Emotion. P. Goldie, ed. New York: Oxford University Press.

Dancy, Jonathan

1993 Moral Reasons. Cambridge, Mass.: Blackwell.

2004 Ethics Without Principles. New York: Oxford University Press.

Deigh, John

1994 “Cognitivism in the Theory of Emotions." Ethics 104(4): 824-854.

Deonna, Julien

2006 "Emotion, Perception and Perspective." dialectica 60(1): 29-46.

Deonna, Julien and Teroni, Fabrice

2009 "L'intentionnalité des émotions: du corps aux valeurs." Revue Européenne des Sciences Sociales 47(144): 25-41.

2012 The Emotions: A Philosophical Introduction. New York: Routledge.

Döring, Sabine

2007 "Seeing What to Do: Affective Perception and Rational Motivation." dialectica 61(3): 363-394.

Goldie, Peter

2004 "Emotion, Feeling and Knowledge of the World." In Thinking about Feeling. R. Solomon, ed. New York: Oxford University Press.

2008 "Misleading Emotions." In Epistemology and the Emotions. G. Bruun, U. Doguoglu and D. Kuenzle, eds. Aldershot: Ashgate.

Griffiths, Paul

1997 What Emotions Really Are. Chicago: The University of Chicago Press. Lyons, William

1980 Emotion. Cambridge: Cambridge University Press.

McDowell, John

1985 "Values and Secondary Qualities." In Morality and Objectivity.

T. Honderich, ed. London: Routledge.

Mulligan, Kevin

2007 "Intentionality, Knowledge, and Formal Objects." Disputatio 2(23): $205-228$.

2010 "Emotions and Values." In The Oxford Handbook of Philosophy of Emotion. P. Goldie, ed. New York: Oxford University Press.

Peacocke, Christopher

2004 The Realm of Reason. New York: Oxford University Press.

Prinz, Jesse

2004 Gut Feelings: A Perceptual Theory of Emotions. New York: Oxford University Press.

Rabinowicz, Wlodek and Rønnow-Rasmussen, Toni

2004 "The Strike of the Demon: On Fitting Pro-attitudes and Values.” Ethics 114(3): 391-423. 
Roberts, Robert

2001 Emotions: An Essay in Aid of Moral Psychology. New York: Cambridge University Press.

Roeser, Sabine

2011 Moral Emotions and Intuitions. New York: Palgrave Macmillan.

Schroeder, Mark

2007 Slaves of the Passions. New York: Oxford University Press.

Siegel, Susanna

2006 "Which Properties are Represented in Perception?" In Perceptual Experience. T. Gendler Szabo and J. Hawthorne, eds. Oxford: Oxford University Press.

Strandberg, Caj

2008 "Particularism and Supervenience." In Oxford Studies in Metaethics Vol. 3. R. Shafer-Landau, ed. New York: Oxford University Press.

Tappolet, Christine

2000 Emotions et valeurs. Paris: PUF.

2011 "Values and Emotions: Neo-Sentimentalism's Prospects." In Morality and the Emotions. C. Bagnoli, ed. New York: Oxford University Press.

Teroni, Fabrice

2007 “Emotions and Formal Objects." dialectica 61(3): 395-415. 